\title{
Pueblos indígenas y la tolerancia occidental: Los derechos humanos como forma sublimada de asimilación*
}

\author{
Cristóbal Gonzalo Carmona Caldera**
}

\begin{abstract}
Resumen: Ignorando la especificidad cultural de su origen y la vaguedad de sus fundamentos, los derechos humanos han sido instituidos como marco en el que se deben desarrollar las relaciones entre los pueblos indígenas y las sociedades occidentales. Sin embargo, ello puede causar más problemas que beneficios en la construcción de un Estado que pretenda perseguir la justicia etnocultural. En el presente trabajo, se analizará de qué forma los derechos humanos se pueden convertir en un arma ideológica que complete la colonización de los pueblos indígenas, considerando sus efectos en la práctica aymara de gestión del agua. Al mismo tiempo, se intentará dilucidar límites más justos para la expresión de la diferencia indígena, a partir de una mediación normativa de la decisión occidental.
\end{abstract}

Palabras clave: Derecho indígena, derechos humanos, multiculturalismo, etnocentrismo

\section{Indigenous people and the western tolerance: Human Rights as a sublimated form of assimilation}

\begin{abstract}
Despite the cultural specificity of its origins and the vagueness of its foundations, human rights have been instituted as the frame where the relations between indigenous people and western societies must take place. But, in the construction of a multicultural state which aims to achieve ethnocultural justice, this can do more harm than good. In this essay, I will analyze in which way human rights can turn into an ideological pretext that allows the completion of the colonization of indigenous peoples, by considering its effects in the aymara administration of the hydric resource. At the same time, I will try to elucidate fairer boundaries for the manifestation of indigenous traditions, by a normative mediation of the western decision.
\end{abstract}

\footnotetext{
* Una primera versión de este artículo fue presentada en el "I congreso de DDHH, Estudiantes de Derecho" de la Facultad de Derecho de la Universidad de Chile. Quisiera agradecer enormemente tanto a Milka Castro como a José Santos Herceg por su constante apoyo, y por sus precisos comentarios a versiones preliminares de este artículo. Asimismo, a Raquel Yrigoyen, quien con sus certeras críticas ayudó a centrar la hipótesis del texto.

** Universidad de Chile, Santiago, Chile. E-mail: c.g.carmona@gmail.com.
} 

ethnocentrism

Key words: Human Rights, indigenous traditions, multiculturalism,

Recibido: 23.03.2009

Aceptado: 10.06.2009

\author{
$* * *$ \\ "Where man is not nature is barren" \\ William Blake, The marriage of Heaven and Hell
}

La emergencia de los pueblos indígenas que ha tenido lugar en América Latina en las últimas décadas (Bengoa 1999), y la consiguiente fisura en el monismo legislativo de la región que ésta provocó, puso en el debate ético-jurídico el tema de los límites de la tolerancia de una sociedad occidental frente a las costumbres -"exóticas", "primitivas" o simplemente "diferentes”- del otro indígena; la pregunta de hasta qué punto la dialéctica integración-diferenciación propia del multiculturalismo ${ }^{1}$, permite configurar una síntesis en la cual se conjuguen adecuadamente los sistemas valóricos y normativos de las culturas en juego.

En Chile, la respuesta a esta problemática fue zanjada con brutal simplicidad. En efecto, el art. 7 de la Ley 19.253 (Ley indígena) permite la diferencia indígena "en todo lo que no se oponga a la moral, a las buenas costumbres y al orden público", homologando burdamente con ello -y respondiendo asimismo a un viejo anhelo liberal-, la distintividad "étnica” a la "religiosa"2. El artículo 54, por otro lado, adolece de similares defectos. Éste se viene a pronunciar sobre aquello que en doctrina se conoce como "conflictos de interlegalidad", esto es, cuando dos sistemas normativos coexistentes en un mismo espacio geopolítico presentan maneras diversas

\footnotetext{
${ }^{1}$ El término "multiculturalismo" se usa en este trabajo para designar el modelo liberal de administración de las diferencias culturales. Con "multiculturalidad”, en cambio, se designará el mero hecho de la convivencia de distintas culturas dentro de un mismo espacio político-administrativo.

${ }^{2}$ Art. $19 \mathrm{~N}^{\circ} 6^{\mathrm{o}}$ : "La Constitución asegura a todas las personas: (...) La libertad de conciencia, la manifestación de todas las creencias y el ejercicio libre de todos los cultos que no se opongan a la moral, a las buenas costumbres o al orden público”. Ya se ha pronunciado Kymlicka sobre la falta de coherencia de esta analogía entre la separación Estado e Iglesia y la separación Estado y etnicidad, ya que, si bien es plausible y deseable que un Estado sea confesionalmente laico, no es posible que se dicha neutralidad se dé en el ámbito cultural: "The state can (and should) replace religious oaths in courts with secular oaths, but it cannot replace the use of English in courts with no language" (Kymlicka 1996: 111). También véase su crítica al "patriotismo constitucional" de Habermas en tanto se contradice al implicar que la ciudadanía debería ser independiente de características etnoculturales o históricas concretas como la lengua y, al mismo tiempo, que una lengua común es indispensable para la democracia (Ibid: 200 note 15).
} 
de resolver un mismo asunto ${ }^{3}$. En nuestro país, si hay un juicio entre indígenas de la misma etnia, el mentado artículo faculta al juez para considerar a la costumbre de su comunidad como “derecho”, eso sí, "siempre que no sea incompatible con la Constitución Política de la República”. De la sola lectura de ambas normas, se vislumbra con meridiana claridad que la apertura moral y jurídica que propicia la Ley indígena, pasaría más por una concesión puramente retórica de derechos que, si bien le permite al Estado solazarse en su adecuación a la normativa internacional, finalmente sólo respeta aquella especificidad cultural administrable en los oxidados marcos del folklore, el etno-turismo y la gastronomía.

Con la reciente ratificación del Convenio 169 sobre Pueblos Indígenas y Tribales en Países Independientes de la Organización Internacional del Trabajo (Convenio 169 OIT) -a entrar en vigencia en septiembre del 2009-, la realidad legislativa chilena se ha acercado a la de los restantes estados andinos (Perú, Bolivia, Colombia, Ecuador y Venezuela), los que, junto a una serie de reformas constitucionales que reconocen el carácter pluricultural del Estado (Ecuador 1998, Bolivia 2009) o la Nación (Colombia 1991, Perú 1993), vienen funcionando hace varios años con el referido convenio. Éste es, actualmente, el único instrumento internacional vinculante a favor de los derechos indígenas, y contiene, en teoría, márgenes más amplios para el desenvolvimiento de las tradiciones de los pueblos originarios, a saber, "los derechos humanos internacionalmente reconocidos" 4 . El mismo criterio se enuncia en el art. 34 de la recientemente aprobada Declaración de Naciones Unidas sobre los Derechos de los Pueblos Indígenas ${ }^{5}$, y se repite sagrada e institucionalmente desde hace años en los escritos de Rodolfo Stavenhagen, ex Relator Especial de la ONU sobre la situación de los derechos humanos y las libertades fundamentales de los indígenas (Stavenhagen 1992), y de su sucesor, James Anaya (Anaya 1996).

Mas hay algo peculiar -si no paradójico- en todo este discurso de consagración de los derechos humanos como minima moralia de las relaciones interétnicas. Para analizarlo, me gustaría detenerme someramente

\footnotetext{
${ }^{3}$ En la definición de Boaventura de Sousa Santos: "Consiste en la coexistencia, dentro de un mismo territorio geopolítico, de un ordenamiento jurídico estatal moderno, occidentalizado, oficial, con una pluralidad de ordenamientos jurídicos locales, tradicionales o recientemente desarrollados, no oficiales, de raigambre comunitaria -en otras palabras, la situación convencional de la pluralidad jurídica” (Santos 1999: 149).

${ }^{4}$ Art. 8,2: "Dichos pueblos deberán tener el derecho de conservar sus costumbres e instituciones propias, siempre que éstas no sean incompatibles con los derechos fundamentales definidos por el sistema jurídico nacional ni con los derechos humanos internacionalmente reconocidos. Siempre que sea necesario, deberán establecerse procedimientos para solucionar los conflictos que puedan surgir en la aplicación de este principio.” Las cursivas son mías.

${ }^{5}$ Art. 34: "Los pueblos indígenas tienen derecho a promover, desarrollar y mantener sus estructuras institucionales y sus propias costumbres, espiritualidad, tradiciones, procedimientos, prácticas y, cuando existan, costumbres o sistemas jurídicos, de conformidad con las normas internacionales de derechos humanos".
} 
en los últimos autores mencionados. Ambos, se infiere ya, defienden la autodeterminación y los derechos colectivos indígenas siempre y cuando calcen con las prescripciones contenidas en las Cartas de Derechos Humanos -plausible propuesta, considerando el hecho teórico de que éstos se suponen, de una forma u otra, meta-contextuales-. Como otros indigenistas ${ }^{6}$, Stavenhagen ilustra las costumbres indígenas que serían prohibidas bajo el imperio de los DDHH, con la clitoridectomía o mutilación genital femenina (Stavenhagen 1992: 134). Y acá, ya hay algo sospechoso. Con todo lo que pudiese repugnar al pensamiento occidental una práctica de esta naturaleza $^{7}$, no parece coherente en un plano teórico -ni siquiera en uno puramente emotivo-, el des-diferenciar una amplia gama de tradiciones vernáculas indígenas -léase diferencias de género, gobiernos no democráticos, etc.-, subsumiéndolas uniformemente junto a la ablación de clítoris, el genocidio o la esclavitud, bajo el epígrafe de "violaciones a los derechos humanos".

Algo parecido, aunque desde otra perspectiva, ocurre con el discurso de James Anaya. Éste establece expresamente la obligación de los pueblos indígenas de regirse según los derechos humanos (Anaya 1996: 55, 109 y 110), mas, cuando hace su defensa de la "integridad cultural” y el derecho de autodeterminación de éstos (Ibid: 98-104), ignora deliberadamente $-y$, hay que decirlo, coherentemente, aunque ello sólo redunde en la esterilidad de su propuesta- aquellos casos de diferencia cultural radical donde se violan normas de derechos humanos, centrándose únicamente en demandas benignas como la utilización de lenguas indígenas en los tribunales o la protección de sus lugares sagrados. Como observa Kymlicka, pocas personas se mostrarían en desacuerdo con un principio de "integridad cultural” que se limitase a estos casos benignos (Kymlicka 2003: 182). Pero es precisamente en aquellas áreas grises, cuando defender prácticas culturales implica indefectiblemente vulneración de principios éticos occidentales $-v$. gr., relaciones de género-, donde se desarrolla el debate más álgido en torno a la "integridad cultural indígena”; áreas sobre las que, sorprendentemente, Anaya no se pronuncia.

Este tipo de discursos, me parece, no es casualidad. Como ha subrayado •i•ek, toda noción ideológica universal -en tanto significado al servicio del poder- siempre está hegemonizada por algún contenido particular que tiñe esa universalidad y explica su eficacia $(\bullet i \bullet e k$ 2005: 137-139). De esta forma, concentrándose sólo en casos extremos -impactantes en uno,

\footnotetext{
${ }^{6}$ En Chile, por ejemplo Bengoa 1995: 8 y 9.

${ }^{7}$ Cabe la precisión de que la mayoría de las mujeres africanas considera más importante el acceso a la tierra que el terminar con esta práctica. De hecho, desde hace algunos años se ha abandonado el discurso de considerarla como una violación de la integridad personal y de la dignidad humana, que era el enfoque dado por las feministas occidentales, centrándose ahora en las nocivas consecuencias para la salud que tendría (Brems 2001: 169). Esto, valga la aclaración, tampoco es un argumento para erradicar dicha práctica, sino simplemente para adecuar los procedimientos de forma que se reduzcan las posibilidades de infección (Gilman 1999).
} 
inocuos en el otro-, es que los autores analizados pueden obviar el debate acerca de la congruencia de establecer normas de raigambre netamente occidental, como límite universal y unívoco para la expresión de la diferencia cultural. Ello, cuando uno debiese tener especial cuidado con el discurso de los derechos humanos, pues en tanto prescriben los "verdaderos" derechos del hombre, se convierten en un fértil nicho ideológico para justificar y legitimar la dominación de otras culturas. El establecer dichas pautas debiese ser sólo el comienzo de la discusión y no el fin de ella.

En una imagen sugerente, Alvin Schmidt se preguntaba si no sería el multiculturalismo el "caballo de Troya” que socavase los más profundos valores y principios occidentales de libertad e igualdad (Schmidt 1997). A una década desde la realización de esta pregunta, después de las reformas ensayadas a lo largo de nuestro continente -las que, sin mostrarse del todo ineficaces, han sido claramente insuficientes- es lícito preguntarse si los derechos humanos representan una frontera justa para la expresión de la diferencia indígena, o si, al contrario, no serán finalmente éstos el "caballo de Troya" a partir del cual se complete la colonización de los "mundos de vida” indígenas.

Por ende, en el presente trabajo intentaré analizar las implicancias que tiene el establecer a los DDHH como "límite de la tolerancia”. Para ello revisaré en primer término el tema de su fundamentación discursiva y las consecuencias que de acá se derivan; luego, con el ejemplo del derecho de propiedad, se mostrará de qué forma la aplicación de los derechos humanos pueden fomentar la aculturación de los pueblos indígenas; finalmente, se esbozará rápidamente una alternativa para repensar el tema de los límites de la tolerancia.

\section{Un orden natural}

La Declaración de los Derechos del Hombre y del Ciudadano, del año 1789, y las que le sucedieron en aquel período ${ }^{8}$, son el referente más obvio de la Declaración Universal de Derecho Humanos (1948) ${ }^{9}$. Aquellas primeras manifestaciones francesas, nacidas en los albores de la revolución, eran universales en el sentido de que enunciaban los derechos del "hombre" en abstracto, basado en el concepto iusnaturalista de una "naturaleza humana”, cuya esencia tratan de salvaguardar. Acá, la palabra “declaración” -como apreció Hervada- no es, en absoluto, gratuita (Hervada

\footnotetext{
${ }^{8}$ Declaración del Hombre y del Ciudadano del Año I (1793); Declaración de los Derechos y Deberes del Hombre y del Ciudadano (1795).

${ }_{9}^{9}$ Aunque, claro, esta opinión no unánime. Mauricio Beuchot, por ejemplo, rastrea la idea de derechos humanos hasta la escolástica de Santo Tomás, haciendo énfasis en el desarrollo que de ella hicieron autores como Vitoria y Las Casas con respecto a la conquista de América (Beuchot 2004)
} 
1986), sino que tendría el sentido técnico de traducir el ordre natural en un ordre positif, de tal modo que el derecho natural fuera meramente reforzado y aplicado en la ley deducida de él (Habermas 1997: 94). En resumidas cuentas, se trataba de trasladar al campo ético el famoso apotegma newtoniano Natura est semper sibi conson ${ }^{10}$, concibiendo una esfera de derechos que no estuviesen determinados por la geografía o el tiempo; que fuesen, en una palabra, universales.

Bajo estos términos, resulta claro que todo juicio cultural que se pronuncie a partir de ellos, se presentaría como "imparcial" u "objetivo", como un juicio no sujeto a provincialismos morales, sino que realizado desde una perspectiva inmaculada contextualmente; lo que hay acá -como lo expresó Montaigne en "De los caníbales” (1578-1580), quizás el primer gran pronunciamiento moderno con respecto al "otro", es un llamado a "juzgar siempre según la voz de la razón y no según la voz común” (Montaigne 1947: 189). Y es en esta retórica esencialista donde, a mi parecer, comienzan los problemas -al menos en lo que a la valoración de otras culturas se refiere-. Ello por la sencilla razón de que, en cuanto se pronuncia un juicio sobre una determinada tradición, a partir -o en defensa- de los "derechos inherentes a la naturaleza humana”, una eventual oposición no sólo significaría ir contra la visión liberal/occidental de dignidad humana, sino en contra de lo que la misma "naturaleza" del ser humano ha prescrito como bueno y decente. Y éste, se sabe, siempre ha sido un buen argumento para la conquista y colonización de otros pueblos; lo sabía Franz Fanon: al final, la objetividad se vuelve siempre contra el colonizado (Fanon 1965: 69) -el ejemplo de EEUU en la actualidad es un triste recordatorio de ello ${ }^{11}$-.

\footnotetext{
${ }^{10}$ [La naturaleza se parece en todas partes]. En este sentido, explica Cassirer que: "Así como la ley de gravedad, que descubrimos en nuestro planeta, no está vinculada a él puesto que nos descubre una fuerza fundamental de la materia, que rige en todo el cosmos y une cada materia de partícula con otra, así también la ley fundamental de la moral actúa en todas las naciones que conocemos". (Cassirer 1994: 273).

${ }^{11}$ Como bien observó • $• \bullet$ ek, el hecho de que la "guerra contra el terrorismo" de Estados Unidos se legitime como el esfuerzo de llevar los derechos humanos a las personas que sufren bajo regímenes fundamentalistas, no puede ser rechazado como una simple hipocresía, sino que apunta a la ambigüedad fundamental que subyace a la referencia de tales derechos en nuestras sociedades (•i•ek 2004: 78). Así, por ejemplo, cuando G. W. Bush dice que "la libertad no es el regalo de América a las naciones, sino que es el regalo de Dios a la humanidad”, es mucho más peligroso que si dijese que la libertad es un regalo de los EEUU a las demás naciones, pues, de ser así, quienes se oponen a los EEUU se estarían oponiendo a un simple Estado-nación. Por el contrario, si la libertad es un regalo de Dios a la humanidad, y los EEUU se perciben como el distribuidor privilegiado de este bien en el mundo, entonces quienes se oponen a los EEUU, se estarían oponiendo al regalo más noble que Dios le dio a la humanidad (•i•ek 2003). Esto legitima una guerra de exterminio, y lleva, como lo explicó José Santos Herceg en su original lectura del "Zum egiwen Frieden" de Kant, a la paz del cementerio, "a que el mundo se transforme en un enorme y eternamente pacífico cementerio” (Santos Herceg 2004: 54).
} 
Lo que asombra, es que se siga sosteniendo un discurso de esta clase -que borra lo que hay de particular y contingente en los derechos humanos, transmutando el mythos indoeuropeo por una Razón humana-, cuando en la actualidad se hace extremadamente compleja una fundamentación iusnaturalista en este sentido. En efecto, las diferentes variantes desplegadas para tratar de cimentar lo apodíctico de estos derechos, desde el iusnaturalismo clásico (Hervada 1986: 427 y 428) hasta los llamados moral rights (Tugendhat 1993: 42 y ss.; García Añón 1992: 77), pasando por el menos teorético “denominador ético común” (Krotz 2004: 158 y ss.), remiten indefectiblemente a un fondo ontológico moral, cuya explicación se enmaraña en tautologías; baste recordar a este respecto, los argumentos desplegados por Bobbio en su contra (Bobbio 2000: 117; Dufour 2004). Después de todo, quizás no sea exagerado exclamar con San Pablo: "Nuestra ciudadanía está en los cielos” (Flp. 3,20), mas no según la interpretación tradicional de la escatología cristiana, sino en relación a que las premisas valóricas fundamentales que uniforman cada sociedad se encuentran, realmente, "en los cielos”: obedecen a la autocomprensión existencial de cada pueblo y, en definitiva, involucran supuestos éticos que no son reducibles a una explicación racional.

Por otro lado, o tal vez a consecuencia de esto, autores como el mismo Bobbio, el jurista argentino Eduardo Rabossi (1987: 148 y ss.) o el filósofo norteamericano Richard Rorty (2000: 69), proponen una omisión intencionada de toda forma de "fundacionalismo" en la materia, por la poca relevancia práctica que tendría: los derechos humanos ya se encuentran positivados en declaraciones suscritas por la mayoría de los países del globo, y lo que hace falta es que se respeten y cumplan. Así, éstos aparecerían puramente como un consenso intersubjetivo -a veces sincero, la mayoría de las veces forzado- entre los Estados. Sin embargo, es evidente que lo que cierto grupo de personas ha acordado como "bueno", dista mucho de ser lo mismo que lo que "la naturaleza del hombre" ha preceptuado como tal. Y esto afecta considerablemente tanto al discurso de "exportación” de los DDHH, como al de su aplicación en culturas no-occidentales.

Por ello, el establecer a los derechos humanos como límite de acción de las costumbres y el derecho indígena -en tanto que obvian e ignoran su propia especificidad- tendería a dispersar arbitrariamente los rasgos culturales indígenas, a la vez que esencializaría la identidad occidental, al establecer un amplísimo núcleo de valores impermeables al "diálogo intercultural". En otras palabras, se asumiría que el "bienestar del hombre" se lograría, solamente, con una organización democrática, indiferente al género, laica y que garantice la propiedad privada sobre las tierras, pero se haría -qué duda cabe- un lugar a la socio-pluralidad, permitiendo sus bailes ancestrales y el uso de trajes autóctonos. Sería ésta, aquella "tolerancia liberal" de la que hablaba •i•ek, en la que se "excusa al Otro folklórico, privado de su sustancia (como la multiplicidad de 'comidas étnicas' en una megalópolis contemporánea), pero denuncia a cualquier Otro 'real' por su 'fundamentalismo' "” (•i•ek 2005: 157), aceptando la mera diferencia inocua, insustancial, aséptica, que no "irrite” a la idiosincrasia occidental. 
A continuación, a manera de ejemplo de lo anterior, examinaré brevemente la fragmentación que produce en la gestión hídrica de los aymaras chilenos -y con ello en su sociedad toda-, el introducir el derecho a la propiedad privada -prerrogativa paradigmática de los derechos inalienables del ser humano, en cuanto se desgrana, como lo vio Locke, de la propia libertad del individuo (Locke 1969: 23)-.

\section{Propiedad, interés y comunidad}

Dentro de una visión animada por la antropomorfización de los elementos naturales del altiplano, el agua es de capital importancia. De hecho, en el mundo andino -aymaras y atacameños-, se podría hablar de la existencia de una verdadera “cultura hídrica” (Castro et al. 1992: 30). En el plano organizacional, sería el "principio general de comunidad” el que definiría su manejo. Dada la escasez del agua, su uso es controlado por normas y sanciones empleadas por la comunidad, estando especialmente referidas a la correcta aplicación de las técnicas para lograr mayor eficiencia. Por ello se dice que la existencia de una organización comunitaria en torno al recurso hídrico, no representa un manejo disperso del mismo. Existe una centralización política, lo cual genera autoridades que conducen el proceso mediante un control fuerte pero igualitario de la irrigación por parte de los usuarios.

El manejo de este recurso llega a contemplar distintos aspectos de la identidad y la cultura aymara. Así, en cualquiera de las múltiples manifestaciones asociadas a la cultura del agua -limpieza de canales, ritos para pedir lluvias, ceremonias para aumentar el caudal de las vertientes, organización para acceder al agua-, concurren, en íntima relación, aspectos económicos, sociales e ideacionales (Castro 1996: 76 y 77). En palabras de Milka Castro, ésta sería una cultura que "se nos muestra indisoluble frente a la gestión del agua” (Ibid: 77).

El vínculo comunitario que se aprecia en el mundo de vida aymara, está en las antípodas de la cosmovisión que rige las relaciones intersubjetivas occidentales. El marcado sentido individualista del derecho moderno, desarrollado por el contractualismo y el constitucionalismo del siglo XIX, y que supone un sujeto autónomo capaz de desenvolverse en el libre mercado, es el que regula y dirige las distintas esferas de la sociedad actual. En este contexto, la propiedad privada se constituye como piedra angular del sistema: como máxima expresión del derecho individual. Ya en la Constitución francesa del año I (1793), se leía: "El gobierno existe para garantizar al hombre el gozo de sus derechos naturales e imprescriptibles (...) La igualdad, la libertad, la seguridad y la propiedad”. La íntima relación que guarda este texto con las declaraciones internacionales de derechos contemporáneas, hace explícito un entramado uniforme, que recorre la modernidad desde sus inicios, y en el que se reconoce a la propiedad privada como expresión simbólica y, al mismo tiempo, condición necesaria para la libertad. Sabida es la intención que tuvo el legislador chileno, en el Código 
Civil, de abolir aquellas instituciones que entrabaran la libre circulación de la propiedad ${ }^{12}$. Ahora, parece claro, el neoliberalismo desplegado en las últimas décadas no hizo sino intensificar esta creencia. La implantación de un modelo de desarrollo capitalista, fundado en la sacralización de la autonomía, de la independencia del hombre ante el medio y la posibilidad de manipulación del mismo, ha guiado las directrices de las políticas públicas desde el régimen militar a la fecha. Respondiendo a ellas, el Código de Aguas dictado en 1981, vino a consagrar el paradigma liberal de la propiedad individual como nueva forma de manejo hídrico.

Amparado bajo el discurso ideológico de ser un "derecho inalienable de la naturaleza humana” -como lo es la propiedad individual- este código ha significado la paulatina desarticulación del derecho consuetudinario aymara, cuyo manejo de las aguas, como ya revisamos, estaba regulado comunitariamente. Este fraccionamiento puede evidenciarse a través de un somero repaso de la normativa y su práctica en el espacio andino.

El Art. 5 del Código de Aguas, luego de señalar que las aguas son bienes nacionales de uso público, agrega que se otorga a los particulares el derecho de aprovechamiento de ellas, derecho sobre el cual la Constitución asegura la propiedad a sus titulares ${ }^{13}$. De esta forma, con su inscripción individual, se establecería un derecho determinado sobre un caudal que, en el caso aymara, es común; este derecho podría transarse en el mercado, permitiendo, por lo tanto, el que particulares ajenos a dichas tierras, obtengan derechos de aprovechamiento sobre aguas que han sido ocupadas históricamente por el pueblo aymara (Albornoz 2000: 879). En el mismo sentido, las “Comunidades de Aguas" establecidas en el Libro III del Código ${ }^{14}$, no hacen sino pauperizar las estructuras organizacionales establecidas de acuerdo al derecho consuetudinario andino. Consagradas en su Art. 187, estas "Comunidades de Agua" "podrán organizarse por escritura pública suscrita por todos los titulares de derechos que se conducen por la obra común”, siendo necesario para ello dos o más personas que tengan derechos de aprovechamiento de las aguas de un mismo canal o embalse, o usen en común la misma obra de captación de aguas subterráneas (Art. 186). En la práctica, "ello significa que al interior de una comunidad rural con control comunal de tierras, podrían existir dos o más 'Comunidades de Agua'. Significa también que las personas al estar en posesión de su derecho pueden transferirlo, y contribuye, además, al debilitamiento del poder de la comunidad andina que se sustenta, en gran parte, en el control y gestión comunal del agua” (Castro 1996: 73).

Respecto a su organización, el Código establece que los negocios que interesen o afecten a la “Comunidad de Aguas”, se resolverán en Junta

\footnotetext{
${ }^{12}$ Se puede revisar, por ejemplo, Alfonso 1892: 24 y 25; y Cood y Fabres 1882: 114.

${ }^{13}$ Art. $19 \mathrm{n}^{\circ}$ 24, inc. 11.

${ }^{14}$ Bajo el epígrafe de "Comunidades de Agua” nos referiremos a la figura jurídica estipulada en el Código de Aguas.
} 
General de Comuneros, en donde el voto de los comuneros se estructura de acuerdo a las acciones que se tengan, las que se establecen, a su vez, en proporción al volumen de aguas que cada comunero maneja dentro de la organización de usuarios. Para las culturas andinas en cambio, es fundamental establecer un voto por regante, por lo que esta norma provoca un serio desajuste en los medios tradicionales de control del recurso.

Se podría señalar al respecto, que el resguardo que se pretende de las aguas dependería más de la cohesión social del pueblo en cuestión (en nuestro caso, el aymara), que de una compatibilización de la Ley con las costumbres y los modos de organización indígenas. Sin embargo, no se debe olvidar, que es la Ley la que viene a desarticular formalmente a la comunidad. Un sucinto ejemplo ayudará a clarificar el panorama. En medio de la implementación del Código de Aguas, con la finalidad de agilizar su aplicación, el Estado financió un programa nacional para fomentar la organización de “Comunidades de Aguas” y la regularización de derechos. Pues bien, dado que el programa comenzó en la zona más septentrional, la región de Tarapacá, por desconocimiento de la nueva legislación, y con una gran urgencia por parte del campesinado de tener un título que asegurara el dominio sobre sus recursos -recordemos que a partir de 1911, por aplicación del Art. 590 del Código Civil, muchas tierras aymaras fueron arrebatadas por el Fisco por no estar inscritas-, un amplio sector de la población optó por formar tales "Comunidades de Aguas", con las consecuencias de desarticulación que hemos revisado. La población atacameña en tanto, al disponer de más tiempo y como reacción a lo ocurrido a sus vecinos del norte, tuvo la capacidad para darse una organización con la finalidad de analizar los efectos de esta disposición. La decisión de los regantes fue rechazar la propuesta gubernamental y exigir la inscripción comunal de sus aguas, de acuerdo al derecho consuetudinario, esto es a nombre de todos los regantes de las comunidades (Ibid.).

En este orden de cosas, las asociaciones propiciadas por el actual Código de Aguas no sólo no representan a las colectividades andinas, sino que la imposición de su paradigma individualista -perfectamente defendible desde un discurso que apela al derecho de cada ser humano de decidir con libertad de qué forma disponer sus bienes- destruye el patrón de estructura, de poder y gestión del recurso hídrico en el pueblo aymara.

Ante el presente ejemplo, es factible objetarme que el potencial de aculturación que hay en el derecho a la propiedad, puede ser de algún modo subvertido o mitigado por una "hermenéutica pluralista"15, que proporcione una lectura de los derechos humanos respetuosa de la las diferencias indígenas; un buen y clásico ejemplo de ello sería la sentencia de la Corte

\footnotetext{
15 "Esta hermenéutica pluralista supone una mirada teleológica que apunta a la construcción e un Estado y sociedad pluralistas, con respeto e los pueblos indígenas y otros colectivos, bajo el principio de igual dignidad de los pueblos y culturas, y la equidad en la redistribución de los recursos sociales” (Yrigoyen 2004:221).
} 
Interamericana de Derechos Humanos sobre el caso Comunidad Mayagna (Sumo) Awas Tingni, del año 2000. En ésta, la Corte realizó una interpretación progresiva del artículo 21.1 de la Convención Americana de Derechos Humanos $(\mathrm{CADH})^{16}$, ampliando el contenido tradicional del derecho de propiedad -como derecho típicamente individual- hacia una concepción más afín a las instituciones indígenas, es decir, como un derecho de ejercicio colectivo y con implicaciones culturales particulares (Nash 2004: 34 y 35). En cierto sentido, lo que hace la Corte es reconocer que infraliminarmente en la CADH se halla una noción occidental de propiedad, la cual, obviamente, no sería propiamente universal y, por lo mismo, es plausible modificarla sustancialmente de acuerdo a otras construcciones culturales. Sin embargo, parece dudoso - por no decir inconcebible- que esta hermenéutica pueda aplicarse a prácticas indígenas que involucran desigualdades de género o formas de gobierno no democráticas.

Algo similar pasa con la idea de "derechos emancipatorios” defendida por Silvina Ramírez. La intención de la autora es proponer una forma de superar los casos de conflicto de derechos humanos y derecho consuetudinario indígena, rechazando de plano toda "ilusión de trascendentalidad" en la resolución de la antinomia (Ramírez 2007: 33 y ss.). A modo de ejemplo de cómo operarían, dice que, ante la contradicción entre el derecho ancestral a la tierra de los pueblos originarios y el derecho a la propiedad privada de un comprador posterior, "el derecho a la tierra de los pueblos indígenas tendría preeminencia sobre otros derechos en juego, dada su vinculación con la supervivencia de su condición de pueblos" (Ibid: 44). Como ya es común en este tipo de literatura, el límite de los derechos emancipatorios se encontraría en aquellas prácticas que "lesionan la médula básica del sistema de derechos humanos” (Ibid: 47), léase violencia contra la mujer o la pena de muerte, pues, al parecer -o al menos según Ramírez, dichas tradiciones no serían esenciales para su integridad cultural como pueblos y, en virtud a la mutabilidad de los sistemas axiológicos, debiesen ser capaces de renunciar a esas costumbres (Ibid). De nuevo, lo que se hace acá es contemporizar con ciertas prácticas indígenas que culturalmente -y, claramente, no bajo un prisma económico (Castro 2000; Yáñez y Molina 2008)- pueden parecer "inocuas", pero se excluye ciertas tradiciones bajo el sugerente discurso de que, según una apreciación foránea, éstas no serían indispensables para su integridad o supervivencia.

Por más que se fuercen los términos, la gran mayoría de los intentos de practicar una hermenéutica pluralista mantiene un "coto vedado” -para usar la expresión de Garzón Valdés- que sigue reclamando una espuria universalidad y que (jsorpresa!) se corresponde con los derechos más apreciados por Occidente. En definitiva, así, los derechos humanos siguen siendo funcionales a la eliminación subrepticia de la diferencia indígena.

\footnotetext{
16 “Toda persona tiene derecho al uso y goce de sus bienes. La ley puede subordinar tal uso y goce al interés social”.
} 


\section{A modo de conclusión: repensando la hegemonía}

En la actualidad, aún para sus defensores más recalcitrantes, es difícil desconocer el semiente occidental de los derechos humanos ${ }^{17}$. Ello explica, en parte, la cantidad de propuestas que el pensamiento filosófico y jurídico contemporáneo ha desarrollado, intentando armonizarlos con las tradiciones vernáculas indígenas -conato que, por lo demás, se encuentra ya en el Convenio 169, aunque no así en la Declaración-. En estas teorías siempre hay -obviamente, con innumerables matices- apelaciones al diálogo entre tradiciones, a la "fusión de horizontes" gadameriana, a las definiciones consensuadas, los tribunales mixtos, etc. En resumen, pérdida de aquella jerarquía innata que ostentaba la civilización occidental y, por lo mismo, propugnar ahora relaciones no ya de subordinación, sino que de coordinación (Yrigoyen 2005). Todo esto, que no quepa duda, me parece una buena idea. Sin embargo, antes de terminar, quisiese esbozar -aun en una forma tan poco prolija y deficiente como la que sigue- una alternativa a ello, o mejor, quisiese simplemente fijar la atención en un punto por lo general inadvertido cuando se discurre sobre estas materias.

Quizás, personalmente, lo que más extrañe en aquellos discursos que tratan de subsanar o atenuar de alguna forma el germen de dominación ínsito en los derechos humanos (v. gr, Parekh 1997: 69-75, 2005: 197 y 198; Santos 1998: 345-367), sea una reflexión -o, en realidad, siquiera una mención- sobre las relaciones de poder presentes en toda noción posible de trans/interculturalidad ${ }^{18}$. En nuestro caso, el hecho más o menos obvio de que los pueblos indígenas, en Chile y otros países latinoamericanos, están dentro de Estados occidentales, y que éstos, al fin y al cabo, ostentan una hegemonía, si bien no epistémica, sí al menos fáctica sobre aquellos. Esto, que puede considerarse una mera perogrullada ante la cotidianidad de las acciones político- administrativas del Estado, imbrica todos los niveles de las relaciones interétnicas, y es incluso ampliable a cualquier forma pensable de "diálogo intercultural”, en tanto tenga pretensiones de ser operativo políticamente hablando.

Imaginemos que se dan todas las instancias pluralistas de participación en la definición intercultural de los DDHH, o mejor aún, demos un paso anterior y situémonos en el momento de la discusión de las normas procesuales o, como alguna vez lo dijo Raúl Fornet-Betancourt, el "diálogo-sobre-los-factores-distorsionadores-del-diálogo"; basta con preguntarse qué pasaría si no se llega a un acuerdo, si se da una situación en donde las posturas sean irreconciliables y en dónde no hay una regulación expresa de cómo resolver el entuerto. Obviamente, la deliberación no puede seguir

\footnotetext{
${ }^{17}$ Un ejemplo de ello, es el proyecto de investigación "Plural legal orders and Human Rights", desarrollado por el International Council on Human Rights Policy (ICHRP), a partir del 2008.

${ }^{18}$ Claro está que ninguno de los autores mencionados se refiere específicamente a las relaciones entre Estado-nación y pueblos indígenas, pero al ocupar la idea de un "diálogo trans/ intercultural", me parece que no hago mucha violencia a sus textos al subsumir dicha relación dentro de sus hipótesis.
} 
indefinidamente, "hasta lograr un acuerdo”. Pues bien, ahí decide, rasga la indefinición, quien tiene el poder de imponer, de romper el juego agonístico con un pronunciamiento. Lo decía Carl Schmitt: "soberano es aquel que decide sobre el estado de excepción” (Schmitt 2005: 5). Y en este caso, parece claro, el soberano es el legislador o, si se quiere, la cultura occidental. Por ello, a mi entender, cualquiera sea la modalidad que se adopte, la estructura de las relaciones interculturales será siempre vertical.

Ahora, en lo que quisiera insistir aquí, es que esta verticalidad no debiese subsanarse invocando algún marco transcultural que trivialice los actos de dominación, dado el peligro que va implícito en un gesto como éste -espero que este trabajo haya servido para demostrarlo-. De hecho, llegados a este punto, quizás lo mejor sería olvidarnos de cualquier intento de disfrazar la hegemonía moderna de "racionalidad" o, peor aún, de "naturaleza humana”, reconociendo en cambio la necesidad de que el conflicto llegue a definirse en términos puramente políticos, que se articulen en la distinción schmittiana de "amigo-enemigo", resolviéndose con una decisión de aquel en el poder (Schmitt 2007: 26 y ss., 69 y ss.) ${ }^{19}$. Esto, me parece, es lo que ocurre en un alto número de re-lecturas pluralistas de los DDHH, que alcanzan su límite de elasticidad en diversos tipos de "violencia y opresión” indígena hacia la mujer, pero que travisten sus argumentos de racionalidad y neutralidad, lo que intensifica la aculturación; en pocas palabras, al final, la línea divisoria se traza desde una opción política, fundada pura y legítimamente en la "lealtad” hacia el grupo político-cultural “nosotros los occidentales"- al que se pertenece (Rorty 2002: 92-97) ${ }^{20}$. Sin duda, y para pánico de muchos, esto sería volver al etnocentrismo; pero en este caso -como lo dijo Heidegger refiriéndose al círculo hermenéutico (2005: 171)-, tal vez lo decisivo no sea salir del etnocentrismo, sino entrar en él de forma correcta. Por lo mismo, las reflexiones finales de este artículo intentarán esbozar sucintamente bajo qué condiciones dicho etnocentrismo puede ser considerado etnoculturalmente justo.

Eso sí, antes de continuar, quisiera precisar que ello no niega en absoluto las oportunidades para que se desarrolle un fructífero y plural diálogo entre sociedad mayor ${ }^{21}$ y pueblos indígenas, en orden a determinar el hasta qué punto éstos gozan de lo que Stuart Hampshire llamó “licencia a la

\footnotetext{
${ }^{19}$ En el Foreword a esta edición, Tracy B. Strong explica que una de las consecuencias de esta categoría, es precisamente que cuando hablamos de "justicia” o "racionalidad", no nos comprometemos en absoluto con el concepto ideológico de "universalidad" o "humanidad" (y todos los peligros que ello implica), sino que nos damos cuenta de "quiénes” somos, y qué es lo que "nosotros” debemos hacer (Strong 2007). Está claro que no comparto todas las premisas de la distinción de Schmitt, pero estimo que es tremendamente útil para conceptuar la situación de que la política se resuelve en una lucha por el poder, en dónde los cursos de acción son definidos por quien posea la hegemonía.

${ }^{20}$ Por esto es que me parece tremendamente acertado el término "imposición” con el que se refiere Sánchez Botero a los “mínimos constitucionales” establecidos por la Corte Constitucional Colombiana para desenvolvimiento de las prácticas indígenas (Sánchez 1998).

${ }^{21}$ Con ello no me refiero a criterios demográficos, sino más que nada socio y politológicos.
} 
diferencia”. En éste, los DDHH jugarían a otro nivel, entendiéndose antes como manifestaciones de derechos fundamentales para Occidente, que como valores a ser compartidos por -cuando no "encontrados” en- las lógicas culturales amerindias. Lo que sí, a riesgo de ser majadero, quisiese insistir en que ello no significa sustraerse de la hegemonía occidental, pues la existencia y operatividad del mentado diálogo se circunscribiría a un espectro de soberanía que, aun cuando no llegue finalmente a expresarse, es inmanente a la estructura de las relaciones interculturales.

En este orden de cosas, el momento de decisión intercultural, al haber renunciado a cualquier postulado meta-ético del cual asirse, se presenta como esencialmente aporético, marcado por la experiencia de la indecidibilidad. Y es acá, precisamente, donde se nos abre la posibilidad de la justicia etnocultural. Como bien decía Derrida, la justicia necesita de la experiencia de la aporía, en tanto experiencia de lo imposible, en tanto momento en que la decisión entre lo justo y lo injusto no está jamás asegurada por una regla; he ahí su diferencia con la justicia del derecho en tanto aplicación de norma (Derrida 2002: 39). En este sentido, lo indecidible no es sólo la oscilación o la tensión entre dos decisiones. Indecidible es la experiencia de lo que siendo extranjero, heterogéneo con respecto al orden de lo calculable y de la regla, debe sin embargo, entregarse a la decisión imposible, teniendo en cuenta el derecho y la regla (Ibid). En este punto, cuando se ha cercenado de antemano toda salida pulcra y aséptica, vale preguntarse por las diversas tensiones que debiesen sopesarse en el espectro del poder soberano, para que su decisión puede ser considerada justa, etnoculturalmente hablando.

Por un lado, poco importa, al momento de decidir qué proscribir y qué permitir, las consideraciones acerca de qué elementos de una cultura podrían ser considerados “contribuciones a la humanidad”, como querría Taylor $^{22}$, o si cada cultura no es un universo cerrado, inefable, sino que, “potencialmente, es todas las culturas”, como exclamaba Feyerabend en su época post-relativista (Feyerabend 1996: 39-42); lo que interesa es que dicha cultura le proporciona a un individuo un haz de significaciones que dan sentido a su vida. Al hablar de "persona”, siempre se recuerda su etimología de “máscara” usada por el personaje teatral en la antigüedad; quizás -y así lo intuyó Wilde- habría que volver a prestar atención a la máscara y olvidarse de la realidad que pueda haber "debajo” de ella, "that dreadful universal thing called human nature” (Wilde 1986: 64 y 65). El derecho y las prácticas indígenas importan en la medida que constituyen el universo simbólico, el "léxico último" ${ }^{23}$ de un determinado pueblo, y no -de nue-

\footnotetext{
${ }^{22}$ Como aclara Susan Wolf en su respuesta al clásico ensayo de Taylor "The politics of recognition", la necesidad del reconocimiento de otras culturas no depende del relativo mérito que pudiesen tener éstas en relación a otras, sino en el hecho de que esas culturas constituyen la cultura de algunos grupos que constituyen nuestra comunidad (Wolf 1994: 81).

23 “Es 'último' -nos dice Rorty- en el sentido de que si se proyecta una duda acerca de esas palabras, el usuario de éstas no dispone de recursos argumentativos que no sean circulares. Esas palabras representan el punto más alejado al que podemos ir con el lenguaje: más allá de ellas está sólo la estéril pasividad o el expediente de la fuerza” (Rorty 1991: 91).
} 
vo- por el posible valor -qué decir verdad- que tenga para gente de otras culturas.

Así, la reflexión y decisión ética occidental debe estar marcada por la "solidaridad" que se tendría para con el indígena americano, en tanto ser susceptible de dolor y humillación (Rorty 1991: 209). Permítaseme explicar en qué sentido. De lo que se parte, es del imperativo liberal de evitar la crueldad, de evitar causar dolor a otros seres ${ }^{24}$. Dentro de las diversas clases de dolor, la humillación, se sabe, remite al ámbito de un dolor que sólo el ser humano puede captar y percibir: se daña la competencia lingüísticosimbólica que nos caracteriza, en cuyo ejercicio construimos y reconstruimos nuestras identidades y diferencias (Figueroa 2007: 172). Para Rorty, la mejor forma de causar un dolor prolongado a una persona es humillarla, haciéndole ver que las cosas que les parecían las más importantes resultan fútiles, obsoletas e ineficaces, obligándola a abandonar sus léxicos últimos de sentido y adoptar uno nuevo, el que se le impone desde la cúpula. Si, entonces, aun dentro del mismo léxico contingente liberal, el imperativo fundamental es no causar dolor, y dentro de esta misma doctrina ideológica el tipo más intenso y particularmente humano de dolor es aquel que proviene de una humillación, entonces se articula plausible y coherentemente para el imaginario occidental, la necesidad de respetar las prácticas y costumbres que constituyen las redes de significación de una cultura indígena.

Pero, al mismo tiempo, no se puede ignorar el punto de origen de la decisión; ésta se halla enclavada y se proyecta desde un nicho cultural determinado: la cultura occidental. El hecho de que se le niegue la universalidad a sus valores no quiere decir, en absoluto, que estos carezcan de importancia; más bien, se trata de circunscribirlos adecuadamente -ya lo decía, de entrar en ellos de forma correcta-. Estructuran el mundo de vida del soberano y, por ende, no puede éste permitir, así sin más, que se vulneren. Es verdad que el adjetivo posesivo que acompaña ahora la enunciación del juicio intercultural -el que toda justicia se lea como su justicia (la justicia según un grupo determinado)-, representa un límite ético: no se debe imponer a otras culturas. Pero si uno aguza la vista, se da cuenta que en dicho adjetivo se superpone otro imperativo, que convive aporéticamente con el primero: el que no puede dejar de aplicarla en asuntos de su soberanía, a riesgo de fragmentar su propio universo simbólico.

En síntesis, se debe reconocer que, en último término, el juicio intercultural se pronuncia desde la parcialidad de una tradición normativa, a saber, la cultura occidental (que es la que ostenta el poder en un Estado multicultural). Sin embargo ésta, sabiendo su propia precariedad epistémica, tiene conciencia de la importancia de los léxicos últimos para la vida de cada persona, por lo que no puede proscribir las costumbres de los pueblos indígenas -que forman y determinan dicho léxico- sin sentir, a su vez, que

\footnotetext{
${ }^{24}$ Bajo esta regla, se podría sustentar también el respeto a los derechos de los animales no humanos (Singer 1999).
} 
hace violencia, que se hace violencia a sí misma -una violencia prohibida, inusitada y abrupta, contraria a sus más íntimas convicciones-. Pensemos por ejemplo, y para salirnos del caso de la clitoridectomía, en un gobierno indígena no democrático ${ }^{25}$. La decisión intercultural deberá considerar que esa práctica, si bien vulnera principios occidentales básicos -principios de los que Occidente está orgulloso y quisiese defender-, es parte de una trama simbólica que constituye la cultura de otra persona, y cuya derogación causaría sufrimiento (humillación) a ésta -sufrimiento que la misma razón occidental considera importante y que quiere evitar-. Así, el pronunciamiento final sobre el límite de la tolerancia occidental, respondería al resultado nunca definido a priori, siempre amargo, siempre violento- de la tensión entre la necesidad de respetar las propias convicciones, y la de evitar causar sufrimiento prohibiendo las convicciones ajenas -lo que, a su vez, corresponde a la necesidad de respeto de las propias convicciones-.

Una experiencia aporética, sin salida calculable ni previsible, siempre traumática, que encuentra la justicia etnocultural en su propia angustia, en aquello que Ricoeur llamó “lo trágico de la acción”, esto es, el tener que zanjar menos entre el bien y el mal, el blanco y negro, que entre lo gris y gris (Ricoeur 1997: 218).

\footnotetext{
${ }^{25}$ Un ejemplo de cómo la configuración democrática, erosiona las bases organizacionales indígenas, se encuentra en el simple caso de las organizaciones legales impulsadas por la Ley 19.253: “(...) estas organizaciones indígenas pasan a ser conducidas por un presidente, un vicepresidente, un secretario y un tesorero (en contraste con los liderazgos tradicionales mapuche ejercidos por el longko, werken, etc.), quienes son electos en base a criterios de mayorías propios de la sociedad dominante, sin considerar criterios de herencia u otros propios de la cultura mapuche. Ello ha resultado, en muchos casos, en el desplazamiento de las autoridades tradicionales, generalmente de más edad, por jóvenes dirigentes funcionales con acceso a la educación o contactos con organismos públicos u ONGs” (IEI/UFRO : 168).
} 


\section{Bibliografía}

Albornoz, P. (2000), “El Pluralismo Jurídico, ¿Una alternativa de Supervivencia para el Derecho Consuetudinario Indígena en Chile? El Caso de las Etnias Andinas y el Uso del Agua”, en Castro, M. (Ed.), Actas del XII Congreso Internacional "Derecho Consuetudinario y pluralismo legal: desafíos en el tercer milenio”, U. de Chile/U. de Tarapacá, Arica.

Alfonso, P. (1892), “De la interpretación de la Ley”, en Revista Forense Chilena, año octavo, Tomo VIII, Santiago.

Anaya, J. (1996), Indigenous Peoples in International Law, Oxford University Press, New York.

Bengoa, J. (1995), “Introducción” a la Declaración de las Naciones Unidas sobre los derechos de las poblaciones indígenas, Instituto de Estudios Indígenas, Temuco.

Idem (1999), La emergencia indígena en América Latina, FCE, Santiago.

Beuchot, M. (2004), Filosofía y derechos humanos (los derechos humanos y su fundamentación filosófica), Siglo XXI editores, México D. F.

Bobbio, N. (2000), “Sobre el fundamento de los derechos del hombre”, en El problema de la guerra y las vías de la paz, Gedisa, Barcelona.

Brems, E. (2001), Human Rights: Universality and Diversity, Ed. Martins, Ivijhoff Publishers, Netherlands.

Cassirer, E. (1994), Filosofía de la Ilustración, FCE, México.

Castro, M. [et. al.] (1992), Cultura Hídrica: Un caso en Chile, UNESCOORCALC, Caracas.

Castro, M. (1996), “Agua, derechos y cultura en los Andes del norte de Chile. Un enfoque desde la Antropología Jurídica”, en Revista Chungará, volumen 29, N 1, Universidad de Tarapacá.

Idem (2000), “Territorios indígenas: una demanda no esperada para el siglo XXI”, en Castro, M. (Ed.), Actas del XII Congreso Internacional "Derecho Consuetudinario y pluralismo legal: desafíos en el tercer milenio", U. de Chile/U. de Tarapacá, Arica.

Cood, E. y Fabres, C. (1882), Explicaciones de Código Civil destinadas a los estudiantes del ramo en la Universidad de Chile, Academia de Leyes i Ciencias Políticas, Santiago.

Derrida, J. (2002), “Del derecho a la justicia”, en Fuerza de Ley. El 'fundamento místico de la autoridad', Tecnos, Madrid. 
Dufor, C. (2004), "Razón, Poder y límite. Observaciones complementarias a propósito del problema de los derechos humanos”, en Ciudad de los Césares $\mathrm{N}^{\circ}$ 68, año XV.

Fanon, F. (1965), Los condenados de la tierra, FCE, México D. F.

Feyerabend, P. (1996), “Contra la inefabilidad cultural. Objetivismo, relativismo y otras quimeras”, en Giner, S. y Scaterzzinni, R. (eds.), Universalidad y diferencia, Alianza editorial, Madrid.

Figueroa, M. (2007), “Richard Rorty: idea y construcción pragmatista de la solidaridad”, en Figueroa, M. y Michelini, D. (Comps.), Filosofía y solidaridad. Estudios sobre Apel, Rawls, Ricoeur, Lévinas, Dussel, Derrida, Rorty y Van Parijs, Ediciones UAH, Santiago.

García Añón, J. (1992), “Los derechos humanos como derechos morales: aproximación a unas teorías con problemas de concepto, fundamento y validez”, en Ballesteros, J. (Editor), Derechos Humanos. Conceptos, Fundamentos, Sujetos, Tecnos, Madrid.

Gilman, S. L. (1999), “'Barbaric’ Rituals?” en Moller Okin, S., Is Multiculturalism Bad for Women?, Princeton University Press, New Jersey.

Habermas, J. (1997), “Derecho natural y revolución”, en Teoría y Praxis. Estudios de filosofía social, Tecnos, Madrid.

Heidegger, M. (2005), Ser y Tiempo, Editorial Universitaria, Santiago.

Hervada, J. (1986), "Problemas que una nota esencial de los Derechos Humanos plantea a la filosofía del derecho”, en Escritos de derecho natural, Eunsa, Pamplona.

Instituto de Estudios Indígenas, Universidad de la Frontera (2003), Los derechos de los pueblos indígenas en Chile. Informe del programa de Derechos Indígenas, LOM Ediciones/ Instituto de Estudios Indígenas de la Universidad de La Frontera, Santiago.

Krotz, E. (2004), "Los Derechos Humanos hoy: de la aculturación al diálogo intercultural”, en Castro, M. (Ed.), Los desafíos de la interculturalidad. Identidad, Política y Derecho, Programa Internacional de Interculturalidad, Vicerrectoría de Investigación y Desarrollo, Universidad de Chile, Santiago.

Kymlicka, W. (1996), Multicultural Citizenship. A liberal theory of minority Rights, Oxford University Press, Oxford.

Idem (2003), “Teoría de los derechos indígenas”, en L.a política vernácula. Nacionalismo, multiculturalismo y ciudadanía, Paidós, Barcelona 
Locke, J. (1969), Ensayo sobre el gobierno civil, Editorial Aguilar, Madrid.

Montaigne, M. (1947), “De los caníbales”, en Ensayos Completos, Tomo I, Iberia, Barcelona.

Nash, C. (2004), “Los derechos humanos de los indígenas en la jurisprudencia de la Corte Interamericana de Derechos Humanos”, en Aylwin, J. (Ed.), Derechos humanos y pueblos indígenas. Tendencias internacionales y contexto chileno, Instituto de Estudios Indígenas, Universidad de la Frontera, Temuco.

Parekh, B. (1997), “A Varied Moral World”, en Moller Okin, S., Is Multiculturalism Bad for Women?, Princeton University Press, New Jersey.

Idem (2005), Repensando el multiculturalismo, Ediciones Istmo, Madrid.

Ramírez, S. (2007), “Igualdad como Emancipación: Los Derechos Fundamentales de los Pueblos Indígenas”, en Anuario CDH, Universidad de Chile, Santiago.

Ricoeur, P. (1997), “La conciencia y la ley. Cuestiones filosóficas”, en Lo justo, Editorial Jurídica de Chile, Santiago.

Rabossi, E. (1987), "La fundamentación de los derechos humanos: algunas reflexiones críticas”, en Valdivia, L. y Villanueva, E. (comps.), Filosofía del lenguaje, de la ciencia, de los derechos humanos y problemas de su enseñanza, UNAM, México.

Rorty, R. (1991), Contingencia, ironía y solidaridad, Paidós, Barcelona.

Idem (2000), “Derechos humanos, racionalidad y sentimentalismo”, en Abraham, T., Badiou, A., y Rorty, R., Batallas éticas, Ediciones Nueva Visión, Buenos Aires.

Idem (2002), “La justicia como lealtad ampliada”, en Filosofía y futuro, Gedisa, Barcelona.

Sánchez Botero, E. (1998), “Construcciones epistemológicas para el conocimiento de los Sistemas de derecho propio y de las justicias indígenas: el caso colombiano”, en America Indígena, Vol. LVIII, N 1 y 2, enerojunio.

Santos, B. (1998), "Hacia una concepción multicultural de los derechos humanos", en De la mano de Alicia. Lo social y lo político en la postmodernidad, Siglo del Hombre editores, Facultad de Derecho Universidad de los Andes, Ediciones Uniandes, Santafé de Bogotá. 
Idem (1999), La globalización del derecho. Los nuevos caminos de la regulación y la emancipación, Universidad Nacional de Colombia, ILSA, Bogotá.

Santos Herceg, J. (2004), "La paz del sepulturero. Actualidad ético-política de Kant”, en Kant y la racionalidad práctica. Homenaje a los 200 años, Ediciones Universidad Católica Silva Enríquez, Santiago.

Schmidt, A. (1997), The Menace of Multiculturalism: Trojan horse in America, Praeger Publishers.

Schmitt, C. (2005), Political Theology. Four chapters on the concept of sovereignty, The University of Chicago Press, Chicago.

Idem (2007), The concept of the political, The University of Chicago Press, USA.

Singer, P. (1999), Liberación animal, Editorial Trotta, Valladolid.

Stavenhagen, R. (1992), “Los derechos indígenas: algunos problemas conceptuales”, en Revista IIDH, Vol. 15.

Strong, T. B. (2007), "Foreword: dimensions of the new debate around Carl Schmitt”, en Schmitt, C., Political Theology. Four chapters on the concept of sovereignty, The University of Chicago Press, Chicago.

Tugendhat, E. (1993), “Justicia y derechos humanos”, en Revista de Filosofía, Vol. XLI-XLII, Universidad de Chile.

Wilde, O. (1986), “The decay of Lying. An observation”, en De profundis and other writings, Penguin Books, London.

Wolf, S. (1994), “Comment”, en Taylor, Ch. [et al.], Multiculturalism. Examining the politics of recognition, Princeton University Press, New Jersey.

Yáñez, N. y Molina, R. (2008), La gran minería y los derechos indígenas en Chile, LOM ediciones, Santiago.

Yrigoyen Fajardo, R. (2004), "Vislumbrando un horizonte pluralista: rupturas y retos epistemológicos y políticos”, en Castro, M. (Ed.), Los desafíos de la interculturalidad. Identidad, Política y Derecho, Programa Internacional de Interculturalidad, Vicerrectoría de Investigación y Desarrollo, Universidad de Chile, Santiago.

Idem (2005), “Caso 2. Hacia una definición e interpretación intercultural de los derechos humanos”, en Sometimiento constitucional y penal de los indígenas en los países andinos en el s. XIX, 2005, Tesis doctoral en derecho, Universidad de Barcelona, Barcelona. 
•i•ek, S. (2003), La estructura de dominación y los límites de la democracia- [En línea]. HTML <www.antroposmoderno.com> [visita 11-07- 2005].

Idem (2004), La revolución blanda, Atuel/Parusía, Buenos Aires.

Idem (2005), “Multiculturalismo o la lógica cultural del capitalismo multinacional”, en Jameson, F. y •i•ek, S., Estudios Culturales. Reflexiones sobre el multiculturalismo, Paidós, Buenos aires. 